\title{
TU/e EmonONEN

\section{A low-power fast start-up crystal oscillator with an autonomous dynamically adjusted load}

\section{Citation for published version (APA):}

Ding, M., Liu, Y. H., Harpe, P., Bachmann, C., Philips, K., \& van Roermund, A. (2019). A low-power fast start-up crystal oscillator with an autonomous dynamically adjusted load. IEEE Transactions on Circuits and Systems I: Regular Papers, 66(4), 1382-1392. [8544016]. https://doi.org/10.1109/TCSI.2018.2880282

\section{Document license:}

TAVERNE

DOI:

10.1109/TCSI.2018.2880282

Document status and date:

Published: 01/04/2019

\section{Document Version:}

Publisher's PDF, also known as Version of Record (includes final page, issue and volume numbers)

\section{Please check the document version of this publication:}

- A submitted manuscript is the version of the article upon submission and before peer-review. There can be important differences between the submitted version and the official published version of record. People interested in the research are advised to contact the author for the final version of the publication, or visit the $\mathrm{DOI}$ to the publisher's website.

- The final author version and the galley proof are versions of the publication after peer review.

- The final published version features the final layout of the paper including the volume, issue and page numbers.

Link to publication

\section{General rights}

Copyright and moral rights for the publications made accessible in the public portal are retained by the authors and/or other copyright owners and it is a condition of accessing publications that users recognise and abide by the legal requirements associated with these rights.

- Users may download and print one copy of any publication from the public portal for the purpose of private study or research.

- You may not further distribute the material or use it for any profit-making activity or commercial gain

- You may freely distribute the URL identifying the publication in the public portal.

If the publication is distributed under the terms of Article 25fa of the Dutch Copyright Act, indicated by the "Taverne" license above, please follow below link for the End User Agreement:

www.tue.nl/taverne

Take down policy

If you believe that this document breaches copyright please contact us at:

openaccess@tue.nl

providing details and we will investigate your claim. 


\title{
A Low-Power Fast Start-Up Crystal Oscillator With an Autonomous Dynamically Adjusted Load
}

\author{
Ming Ding ${ }^{\circledR}$, Member, IEEE, Yao-Hong Liu ${ }^{\circledR}$, Senior Member, IEEE, Pieter Harpe ${ }^{\circledR}$, Senior Member, IEEE, \\ Christian Bachmann, Kathleen Philips, and Arthur Van Roermund ${ }^{\circledR}$, Senior Member, IEEE
}

\begin{abstract}
An energy-efficient fast start-up method for crystal oscillators is presented, which enables aggressive duty-cycled operation of IoT radios to minimize overall power consumption. A digitally controlled crystal oscillator using the proposed startup technique in $90-\mathrm{nm}$ CMOS is presented. Thanks to the dynamically adjusted load, the negative resistance is boosted, achieving a 13x start-up time reduction and an overall power of $95 \mu \mathrm{W}$ for a $24-\mathrm{MHz}$ crystal oscillator at $1 \mathrm{~V}$. A fully autonomous feedback loop detects the oscillators envelop and adjusts the load capacitance at start-up. Thanks to the low-power start-up circuits, both the start-up time and the start-up energy are reduced. In addition, the robustness and versatility of the proposed method is verified by measuring quartz crystals with different frequencies and quality factors, as well as measuring against temperature, supply voltage, and load capacitance variations.
\end{abstract}

Index Terms - Crystal Oscillator, fast start-up, low-power, IoT, negative resistance, variation-tolerant.

\section{INTRODUCTION}

W IRELESS sensor nodes (WSN) in Internet-of-Things (IoT) applications require an accurate frequency reference $(\sim \mathrm{MHz})$, which generates a stable reference clock for the PLL to synthesize a carrier and to derive clocks for all other parts of the transceiver SoC. To meet the requirements of IoT radios, high performance is desired for the frequency reference. For instance, low-phase noise is required for IoT radios to meet the requirement of adjacent channel interference and also transmission modulation quality. In addition, robust communication among IoT radios requires a small frequency error as well as high stability over environmental variations. For example, a popular standard such as Bluetooth-Low-Energy (BLE) requires that the transmission frequency error should be within $\pm 41 \mathrm{ppm}$ (parts per million) of the desired frequency [1]. This leads to a great challenge for on-chip CMOS oscillators, of which the

Manuscript received June 18, 2018; revised September 26, 2018 and October 21, 2018; accepted November 5, 2018. Date of publication November 26 , 2018; date of current version March 15, 2019. This paper was recommended by Associate Editor N. Krishnapura. (Corresponding author: Ming Ding.)

M. Ding is with the imec-nl/Holst Centre, $5656 \mathrm{AE}$ Eindhoven, The Netherlands, and also with the Eindhoven University of Technology, $5612 \mathrm{AZ}$ Eindhoven, The Netherlands (e-mail: Ming.Ding@imec-nl.nl).

Y.-H. Liu, C. Bachmann, and K. Philips are with the imec-nl/Holst Centre, 5656 AE Eindhoven, The Netherlands.

P. Harpe and A. Van Roermund are with the Eindhoven University of Technology, 5612 AZ Eindhoven, The Netherlands.

Color versions of one or more of the figures in this paper are available online at http://ieeexplore.ieee.org.

Digital Object Identifier 10.1109/TCSI.2018.2880282 frequency error is several orders worse [2]. To improve the performance, the oscillator has to consume significantly more power $(\sim \mathrm{mW})$ [3], which is too much for an IoT radio [4]. As a result, crystal oscillators (XO) have been widely used as the frequency reference in IoT radios thanks to their high quality factor (tens of thousands) [5], which enables high performance [6]-[18].

For IoT radios, low-power is essential to achieve long battery life time. To do that, the transceiver is only activated when transmitting or receiving, and disabled to save power when not needed. In this way, the overall system power is reduced without degrading the performance of the radio. But this requires swift start-up behavior for the whole transceiver. This is relatively easier for the transmitter/receiver, the Phase-Locked-Loop (PLL), and the Power-ManagementUnit (PMU), whose start-up time is up to a few $\mu$ s [4]. Due to the high quality factor, the typical start-up time $\left(\mathrm{T}_{\mathrm{S}}\right)$ of an $\mathrm{XO}$ is, however, relatively long ( ms) [6]-[8], [19]-[23]. In applications with a short off-time, the XO can therefore not be switched off and on in time. Thus, it has to be always active, thereby increasing the off-state power of the whole system significantly. In applications with a short on-time, the XO can be switched on and off, but the extra power due to the startup process can not be neglected. In a duty-cycled radio with a relatively short packet format (for instance the packet length can be as short as $128 \mu \mathrm{s}$ in BLE), the power overhead due to the XO start-up process can go beyond 25\% [24]. Therefore, a reduction of the XO start-up time of the XO is necessary, and at the same time, the energy overhead to enable a fast start-up should be minimized in order to reduce the overall energy consumption.

The XO start-up time, $\mathrm{T}_{\mathrm{s}}$, not only depends on its quality factor and oscillation frequency, but also on its negative resistance $\left(\mathrm{R}_{\mathrm{N}}\right)$ [25] and its internal noise [26] at start-up (Fig. 1). Prior-art tried to reduce the start-up time from the following aspects: increase the $\left|R_{N}\right|$ [27], or increase the initial oscillation energy by injecting another signal at the start-up [24], [28], or a combination of the two techniques [29]. Increasing the transconductance $\left(\mathrm{g}_{\mathrm{m}}\right)$ of the amplifier by providing a higher bias current has been widely adapted to boost $\left|R_{N}\right|$, thus reducing $T_{s}$ [27]. This method reduces the start-up time, but at the sacrifice of increased start-up power consumption (Fig. 1(a)). Furthermore, the effectiveness of this method is limited by the finite voltage headroom of the devices in the analog circuitry. 


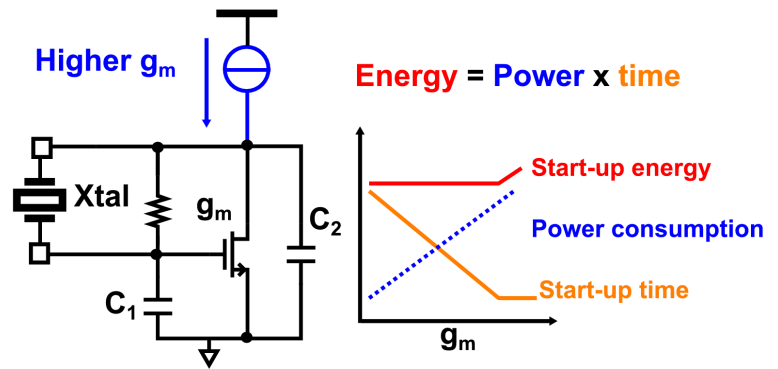

(a)

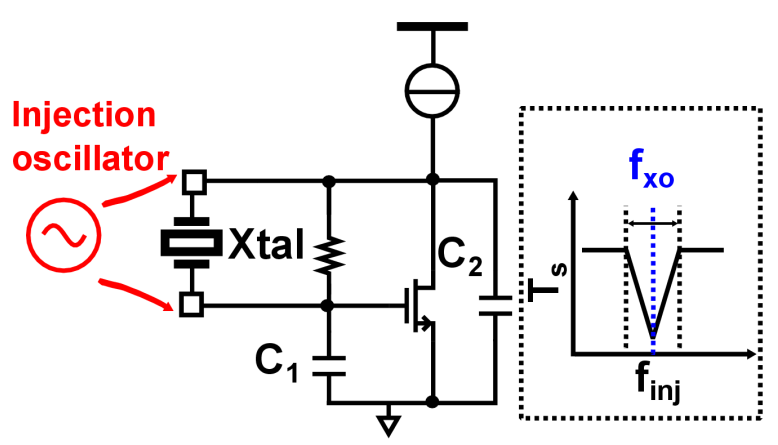

(b)

Fig. 1. Illustration of start-up time reduction techniques: increasing $g_{m}$ (a) and frequency injection (b).

The oscillators presented in [24], [28], and [30] increase their initial oscillation energy to reduce $\mathrm{T}_{\mathrm{s}}$ by injecting either a single-tone [28], [30], or a dithered signal [24]. They require a separate RC oscillator, and its frequency has to be calibrated sufficiently close to the resonant frequency of the crystal oscillator (Fig. 1(b)). This is not convenient because the frequency of an RC oscillator is vulnerable to PVT (process, supply voltage, and temperature) variations. [30] is able to overcome most issues, but requires a very good PVTcompensated design in order to guarantee the performance. To make the frequency injection method less sensitive to PVT variations, Chirp Injection (CI) is introduced in [23] and [29] by sweeping the frequency of the injection oscillator over a certain range. However, the improvement in reduction of startup time is then limited.

In this work, to reduce the start-up time while minimizing the overhead in energy, area and system complexity, a dynamically-adjusted load (DAL) method is proposed [31], [32]. The proposed DAL technique reuses the XO clock once it is available to achieve an automatic control as shown later. The proposed technique achieves a short start-up time $(200 \mu \mathrm{s})$ and low start-up energy $(<40 \mathrm{~nJ})$.

Section II introduces an application which requests aggressive duty-cycling and thus requires an energy-efficient startup method for the crystal oscillator. Section III introduces the design considerations of a crystal oscillator. In section IV the implementation of the crystal oscillator is shown. The measurement results will be presented in section $\mathrm{V}$ and conclusions will be drawn in section VI.

\section{FAST StART-UP FOR BLE AdVERTISING}

As mentioned, WSNs rely on a small duty-cycling ratio to reduce its average system power consumption. BLE radios

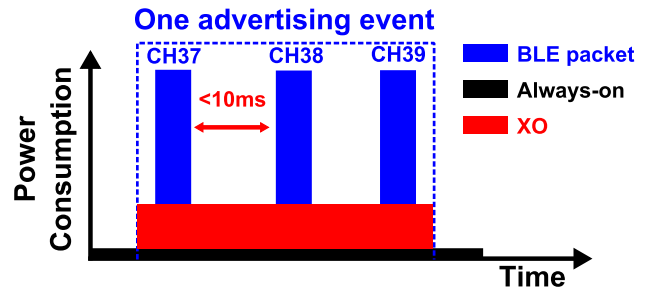

(a)

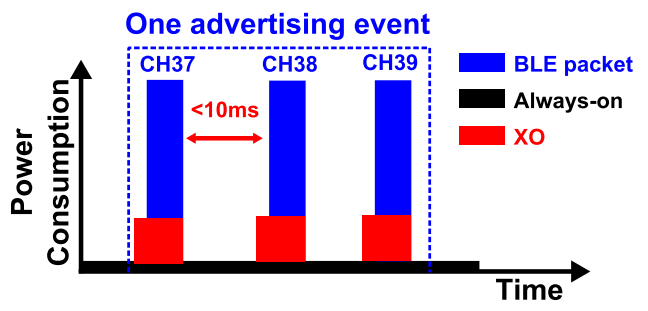

(b)

Fig. 2. Illustration of typical BLE advertising (a) and the fast start-up facilitated BLE advertising (b).

has been ubiquitously deployed and easily accessible through battery-powered mobile devices. Small duty-cycling ratio is essential to assure a long battery life time, considering the relatively high power consumption of the radios ( $\sim \mathrm{mW}[4])$. In a typical BLE advertising event, the main radio is asleep most of the time, and only activated when broadcasting. During each advertising event, three packets are transmitted over three channels $\mathrm{CH} 37, \mathrm{CH} 38$, and $\mathrm{CH} 39$ consecutively, which are located at frequencies of $2402 \mathrm{MHz}, 2426 \mathrm{MHz}$, and $2480 \mathrm{MHz}$ respectively (Fig. 2(a)). The shortest packet has a short format of $128 \mu \mathrm{s}$. The event interval between two consecutive advertising events is between $10 \mathrm{~ms}$ to $10.24 \mathrm{~s}$, during which the BLE transceiver has sufficient time to be switched off and on to save power. However, within each advertising event, the interval between each packet is no more than $10 \mathrm{~ms}$, which is in the same order as typical start-up time of crystal oscillators. For this reason, the XO can not be switched off and has to be always on, consuming power while the BLE transceiver is in off-state. To minimize the power consumption, the time interval between two packets is kept short. However, this increases the chance that two or three advertisement packets will collide with one interference and the whole advertisement event will be blocked.

Alternatively, if the XO start-up time can be reduced sufficiently in a power-efficient way, the XO can also be switched off between two advertising packets (Fig. 2(b)). In this way, the power consumption of the XO can be reduced with a factor of more than $10 \times$, leading to significant overall power consumption reduction. Moreover, thanks to the short XO start-up time, the interval between two advertising packets can be increased without introducing power overhead of the XO. In this way, the chance that all the three advertising packets collide with a strong interference is reduce significantly, leading to a better communication quality.

The essential to enable the proposed BLE advertising is a power-efficient start-up approach for crystal oscillator, which will be introduced in the next section. 


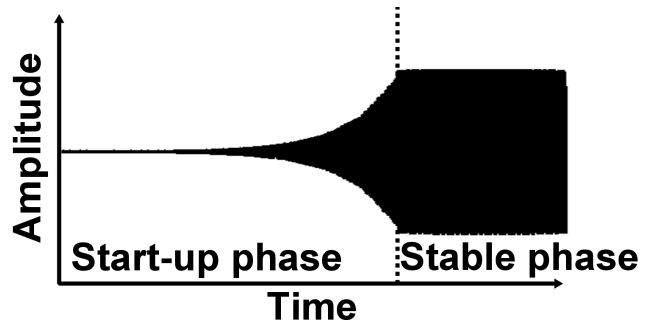

(a)

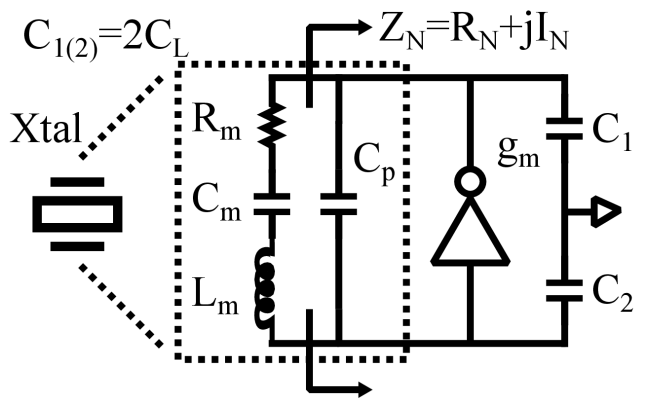

(b)

Fig. 3. Start-up behavior illustration (a) and simplified block diagram of a Pierce crystal oscillator with lumped model (b).

\section{DyNAMiCALLY-AdJUSTED LOAD METHOD FOR FAST START-UP}

For a crystal oscillator in a duty-cycled wireless sensor node, once enabled, the process can be roughly divided into two phases: start-up phase and stable phase Fig. 3(a). In the start-up phase, the amplitude of the oscillator ramps up and reaches a stable value in the stable state, in which the crystal oscillator clock can be used by other building blocks of the chip. In the stable phase, the performance of the crystal oscillator should be sufficient for the RF blocks. In addition, the overhead of the start-up method in energy, area and system complexity should be minimized.

Fig. 3(b) shows the simplified block diagram of a popular Pierce crystal oscillator. The crystal quartz can be lumped with $\mathrm{L}_{\mathrm{m}}, \mathrm{C}_{\mathrm{m}}, \mathrm{R}_{\mathrm{m}}$ and $\mathrm{C}_{\mathrm{p}}$ as the motional inductor, capacitor, resistor and parallel parasitic capacitor. In order for a crystal oscillator to start-up, the loss of a quartz crystal $\mathrm{R}_{\mathrm{m}}$ should be compensated by a negative resistance $R_{N}$, which is given by [25]

$$
\left|R_{\mathrm{N}}\right|=\frac{\mathrm{g}_{\mathrm{m}} \mathrm{C}_{1} \mathrm{C}_{2}}{\left(\mathrm{~g}_{\mathrm{m}} \mathrm{C}_{\mathrm{p}}\right)^{2}+\omega^{2}\left(\mathrm{C}_{1} \mathrm{C}_{2}+\mathrm{C}_{2} \mathrm{C}_{\mathrm{p}}+\mathrm{C}_{1} \mathrm{C}_{\mathrm{p}}\right)^{2}},
$$

where $C_{1(2)}=2 C_{L}$. In the start-up phase, the key to reduce the start-up time is to increase $\left|\mathrm{R}_{\mathrm{N}}\right|$ as much as possible. For a crystal oscillator, $\mathrm{C}_{1(2)} \gg C_{\mathrm{p}}$, and $\mathrm{R}_{\mathrm{N}}$ can be approximated by $-\frac{g_{m}}{\left(2 \omega C_{L}\right)^{2}}$, where $\omega$ is the oscillation angular frequency and load capacitance $C_{L}$ equals $0.5 C_{1(2)}$. It can be seen that $R_{N}$ is approximately quadratic to $1 / \mathrm{C}_{\mathrm{L}}$, so reducing $\mathrm{C}_{\mathrm{L}}$ is very effective to obtain a higher $\left|R_{N}\right|$ at start-up. Considering that $\mathrm{g}_{\mathrm{m}}$ can be limited by the voltage headroom of the analog circuits [27], reducing $\mathrm{C}_{\mathrm{L}}$ can overcome the bottleneck of voltage headroom to boost $R_{N}$. This gives an additional advantage for low supply voltage designs in modern CMOS technologies. In addition, the required minimum $\mathrm{g}_{\mathrm{m}}$ for a crystal oscillator

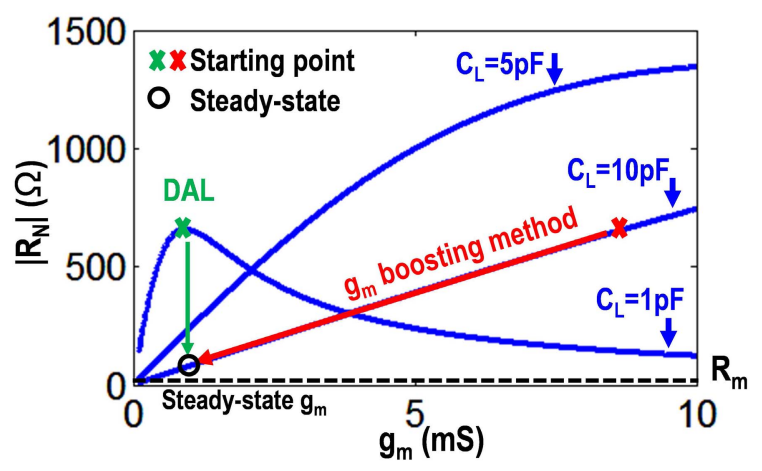

Fig. 4. Comparison of $g_{m}$ method and DAL method.

to start-up is proportional to $\mathrm{R}_{\mathrm{m}}\left(2 \omega \mathrm{C}_{\mathrm{L}}\right)^{2}$ [25], indicating that less power is needed for crystal oscillators with smaller $\mathrm{C}_{\mathrm{L}}$ for start-up. Therefore, in the start-up phase, a smaller $\mathrm{C}_{\mathrm{L}}$ is desired to reduce both start-up time and power consumption.

In the stable phase, the frequency pulling factor $\left(\sim \frac{C_{m}}{2 C_{p}+2 C_{L}}\right)$ [25] indicates the difference between the real oscillation frequency and the intrinsic resonant frequency of a quartz crystal. A large $C_{L}$ is preferred for a quartz crystal as it results in a small frequency pulling factor and thus a small frequency error, which is desired for radio. In addition, a large $\mathrm{C}_{\mathrm{L}}$ also improves stability over environmental variations.

Reference [17] proposes to increase $R_{N}$ by isolating the parasitic shunt capacitor $\mathrm{C}_{\mathrm{p}}$ of the quartz crystal during startup. Reference [18] proposes to increase $R_{N}$ by programming the load capacitance to one small value and to another large value after a delay, but did not provide insight how to optimize start-up time and energy and lacks the feedback loop to automatically increment the load capacitor $\mathrm{C}_{\mathrm{L}}$. In practice, the relation between $R_{N}$ and $g_{m}$ is more complicated (eq. 1), which is illustrated in Fig. 4. The required $g_{m}$ of a crystal oscillator is proportional to $\left(\omega \mathrm{C}_{\mathrm{L}}\right)^{2}$ [25]. For example, for a crystal oscillator with $10 \mathrm{pF}$ load capacitance, $\mathrm{g}_{\mathrm{m}}$ has to be relatively high for fast start-up. Compared to the $\mathrm{g}_{\mathrm{m}}$ method, the DAL method temporarily sets the load capacitance to a smaller value such that during start-up a much smaller $\mathrm{g}_{\mathrm{m}}$ is necessary to achieve the same $\left|R_{N}\right|$. In this way, the DAL method is more energy-efficient compared to the $\mathrm{g}_{\mathrm{m}}$ method. For each load $\mathrm{C}_{\mathrm{L}},\left|\mathrm{R}_{\mathrm{N}}\right|$ increases with $\mathrm{g}_{\mathrm{m}}$ within a certain range. However, if the $g_{m}$ is larger than its value where $\left|R_{N}\right|$ is optimal, $\left|R_{N}\right|$ will decrease due to the $g_{m}$-boosted effect on $\mathrm{C}_{\mathrm{p}}$, which is not desired (Fig. 4). It is worthwhile to mention that a larger $C_{L}$ leads to a larger theoretical peak $\left|R_{N}\right|$ (Fig. 5), but at the cost of much higher power as mentioned before.

In addition, to quantitatively analyze the start-up time $\mathrm{T}_{\mathrm{s}}$ and start-up energy $E_{s}$ for a given crystal oscillator, they are computed and simulated versus the transconductance $\mathrm{g}_{\mathrm{m}}$ and load capacitance $\mathrm{C}_{\mathrm{L}}$ in Matlab. The start-up time for a given crystal oscillator can be estimated as [26], [29]:

$$
T_{\mathrm{s}}=\frac{2 L_{m}}{\left|R_{N}\right|-R_{m}} \ln \left(\frac{0.9 \omega C_{T} V_{D D}}{\left|I_{M(0)}\right|}\right),
$$

where $C_{T}$ is defined as $\frac{C_{1} C_{2}}{C_{1}+C_{2}}+C_{p}, V_{D D}$ is the supply voltage and $I_{M(0)}$ is the amplitude of the current in the node containing 


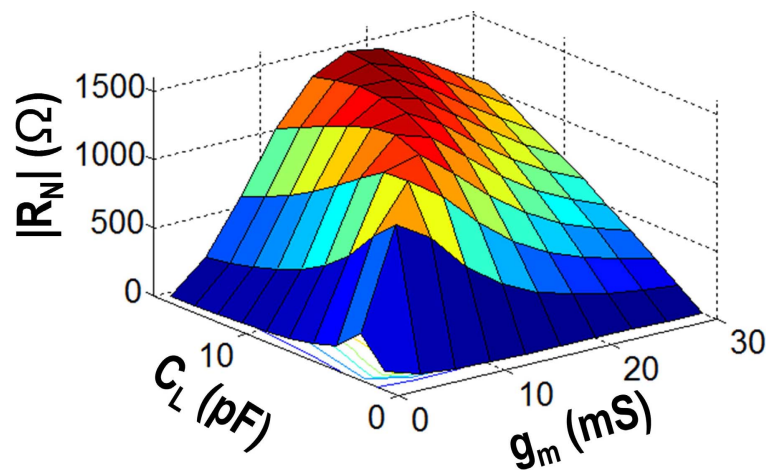

Fig. 5. Simulated $\left|R_{N}\right|$ versus $g_{m}$ and load capacitance $C_{L}$.

the quartz crystal. $T_{S}$ is the time to reach steady-state, and $\frac{2 L_{m}}{\left|R_{N}\right|-R_{m}}$ equals the time constant, $\tau$, of the amplitude exponential growth [26]. The relationship between the start-up time $T_{s}$ and $g_{m}$ and $C_{L}$ is calculated and shown in Fig. 6. For each load capacitance, there is an optimum $g_{m, o p t}$ that results in a minimum start-up time $T_{s}$. This is because $\left|R_{N}\right|$ is maximal at $g_{m, o p t} . T_{s}$ increases at a smaller or larger $g_{m}$ due to the decrease of the $\left|R_{N}\right|$. When $\left|R_{N}\right|$ approaches $R_{m}, T_{s}$ goes up rapidly. Once $\left|R_{N}\right|$ drops below $R_{m}$, the crystal oscillator will fail to start up. The optimum value for $g_{m}, g_{m, o p t}$, is expressed as [25]:

$$
g_{\mathrm{m}, \mathrm{opt}}=\omega\left(C_{1}+C_{2}+\frac{C_{1} C_{2}}{C_{p}}\right) .
$$

The equation shows that $g_{m, o p t}$ is proportional to its load capacitance $C_{1(2)}$ (Eq. 3). Therefore, for crystal oscillators with smaller load capacitance $C_{L}$, a smaller $g_{m}$ is needed. The start-up time at $g_{m, o p t}$ can be expressed as:

$T_{\mathrm{s}, \mathrm{opt}}=\frac{2 L_{m}}{1 /\left(2 \omega C_{p}\left(1+\frac{\left(C_{1}+C_{2}\right)}{C_{1} C_{2}} C_{p}\right)\right)-R_{m}} \ln \left(\frac{0.9 \omega C_{T} V_{D D}}{\left|I_{M(0)}\right|}\right)$.

The theoretical maximum $\left|R_{N}\right|$ for crystal oscillators with smaller $C_{L}$ is lower than that with higher $C_{L}$ (Fig. 4 and Fig. 5). As a result, the $T_{s, o p t}$ for crystal oscillators with smaller $C_{L}$ is larger than that with larger $C_{L}$ (Fig. 6). The measured start-up time of this realized crystal oscillator (two points as shown in Fig. 6) is close to the calculated optimum point for $C_{L}=2 \mathrm{pF}$.

With the calculated start-up time, the total energy during the start-up is further calculated as follows:

$$
\begin{aligned}
E_{\mathrm{s}} & =V_{D D} \times I_{d} \times T_{s} \\
& =\frac{V_{D D} L_{m}}{V_{O V}} \frac{g_{m}}{\left|R_{N}\right|-R_{m}} \ln \left(\frac{0.9 \omega C_{T} V_{D D}}{\left|I_{M(0)}\right|}\right),
\end{aligned}
$$

where $V_{O V}$ is the overdrive voltage of the transistor that generates the negative resistance and $I_{d}$ is the current consumption of the crystal oscillator, which can be estimated as $g_{m} V_{O V} / 2$ assuming $V_{O V}$ is constant. As shown in Fig. 7, for each load capacitance $C_{L}$, there is an optimum range for $g_{m}$ that results in a minimum start-up energy. Within this range, as $g_{m}$ increases, start-up time $T_{S}$ decreases, and the start-up energy remains the same. When combining Fig. 6 and Fig. 7, it can

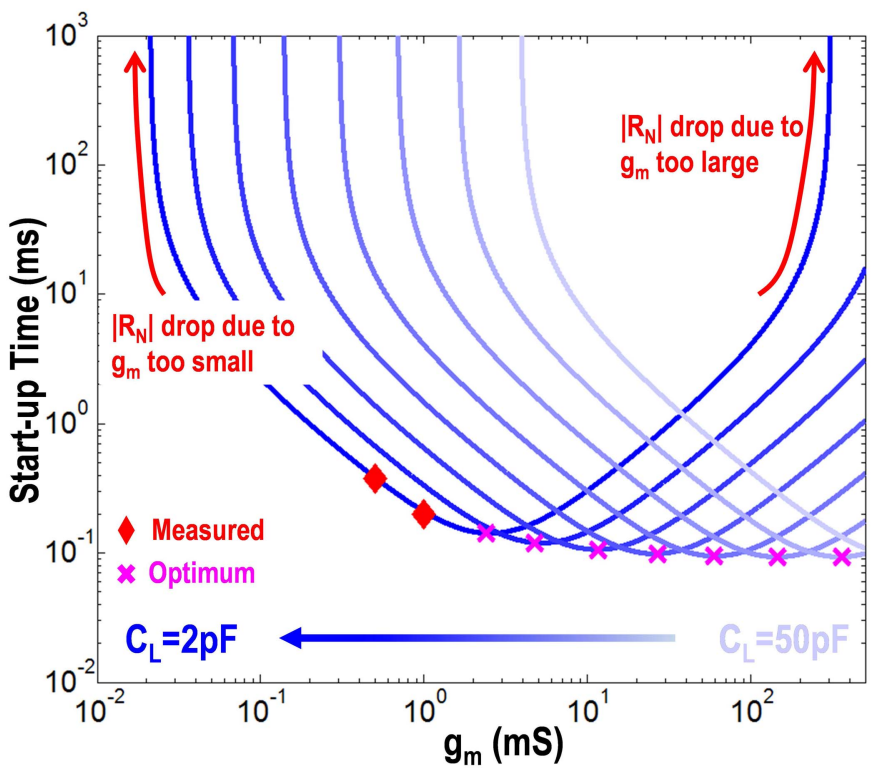

Fig. 6. Simulated start-up time $\mathrm{T}_{\mathrm{S}}$ versus $\mathrm{g}_{\mathrm{m}}$ and load capacitance $\mathrm{C}_{\mathrm{L}}$. $L_{m}=5.8 \mathrm{mH}, R_{m}=20 \Omega, \omega=2 \pi \times 24 \mathrm{M} \mathrm{rad} / \mathrm{s}, V_{D D}=1 \mathrm{~V}, \mathrm{I}_{M(0)}=5 \mathrm{nA}$.

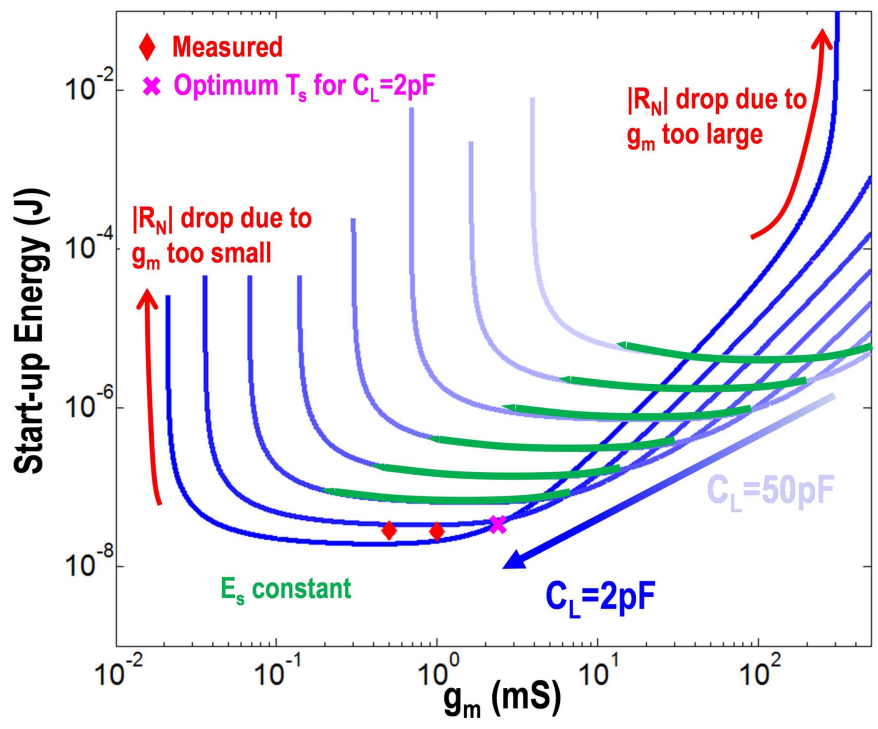

Fig. 7. Simulated start-up energy $E_{S}$ versus $g_{m}$ and load capacitance $C_{L}$. $L_{m}=5.8 \mathrm{mH}, R_{m}=20 \Omega, \omega=2 \pi \times 24 \mathrm{M} \mathrm{rad} / \mathrm{s}, V_{D D}=1 \mathrm{~V}, \mathrm{I}_{M(0)}=5 \mathrm{nA}$.

be observed that if the circuit is optimized for startup-time $T_{S}$, this leads to a near-optimal start-up energy $E_{S}$ directly. However, a circuit optimized for start-up energy $E_{s}$ is not necessarily achieving the optimum start-up time $T_{s}$. As $g_{m}$ further increases, due to the $\left|R_{N}\right|$ degradation, see Fig. 4, the start-up time will increase, and thus the start-up energy will increase. The minimum start-up energy for a crystal oscillator with $C_{L}=2 \mathrm{pF}$ is approximately $200 \times$ lower than that with $C_{L}=50 \mathrm{pF}$. This gives an indication that start-up with smaller $C_{L}$ can save energy significantly, which is also shown in Fig. 7.

To optimize both the start-up performance and the frequency stability of the stable state, in this work, an XO with a dynamically-adjusted load (DAL) technique is proposed, minimizing the $\mathrm{C}_{\mathrm{L}}$ in the start-up phase at first for fast startup and thereafter incrementing $\mathrm{C}_{\mathrm{L}}$ for stable operation in the 


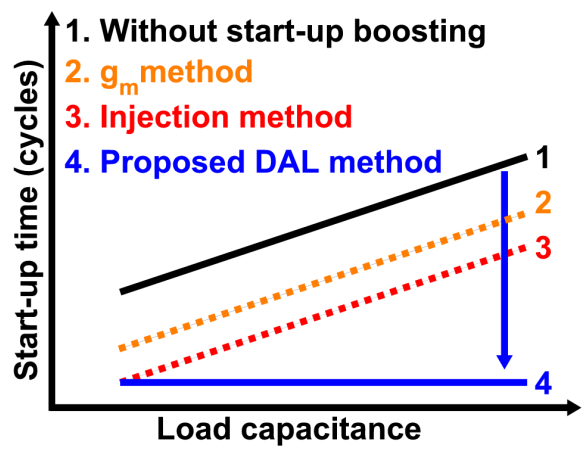

(a)

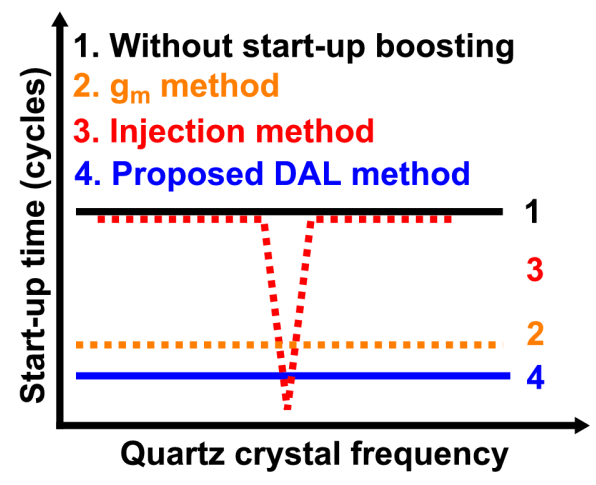

(b)

Fig. 8. Comparison of various start-up approaches with respect to load capacitance (a) and XO frequency (b).

stable phase. As a result, both the start-up time and the startup energy can be reduced. In the stable phase, the operation condition (e.g, load capacitance) of the crystal oscillator is correctly configured, and the performance in the stable phase is not sacrificed as shown later.

In the proposed method, the load capacitance at the startup remains similar regardless of the $\mathrm{C}_{\mathrm{L}}$ used in the stable phase of different quartz crystal (Fig. 8(a)). This allows a larger $\mathrm{C}_{\mathrm{L}}$ to be employed to improve the tolerance to the parasitics changes without increasing the start-up time. In addition, for the frequency injection method, when the frequency of the crystal oscillator is changed (for example, due to a different quartz frequency), the injection oscillator has to be re-designed, otherwise it will not be effective in reducing the start-up time (Fig. 8(b)). The proposed method is less sensitive to such frequency variations since no frequency injection is required.

\section{IMPLEMENTATION OF THE CRYSTAL OSCILLATOR}

Fig. 9 shows the block diagram of the fast start-up XO with the proposed DAL as well as an illustration of its start-up behavior in the time domain. It consists of a Pierce oscillator as its core, a reconfigurable bias current circuitry, two switched capacitor banks $\left(\mathrm{C}_{1 \mathrm{a}(2 \mathrm{a})}\right)$, and a feedback loop to implement the DAL. The proposed dynamically-adjusted load method is implemented through the feedback loop, which works as follows (Fig. 9(b)): $\mathrm{C}_{1 \mathrm{a}(2 \mathrm{a})}$ is reduced to minimum to boost the negative resistance $R_{N}$, facilitating a fast start-up. Therefore, the amplitude of the oscillator is able to ramp up in a short time. A clock detector in the feedback loop is continuously monitoring the amplitude of the oscillator, and will decide if the crystal oscillator has a sufficient output swing to provide a clock for the digital circuit. If so, a finite state machine (FSM) will automatically increase $\mathrm{C}_{1 \mathrm{a}(2 \mathrm{a})}$ to the targeted value. During the start-up, the frequency of the crystal oscillator deviates from the nominal frequency (maximum hundreds of ppm as shown later) because of the frequency pulling effect due to the varying capacitor value $\left(\mathrm{C}_{1 \mathrm{a}(2 \mathrm{a})}\right)$. This frequency offset error is not a problem because it is still sufficient for operation of the digital circuits in the feedback loop. Besides, once $\mathrm{C}_{1 \mathrm{a}(2 \mathrm{a})}$ is set, the oscillator frequency settles to the correct value automatically after a few $\mu$ s delay. After this latency the RF circuits can be switched on, as the oscillator is fully settled then. Note that the whole start-up process is fully autonomous without requiring an extra oscillator or sequence. This makes it possible to implement the DAL method with only an enable signal, which is very convenient for many IoT applications. In addition, it is worthwhile to mention that, thanks to the switched capacitor bank, the frequency of the oscillator can be trimmed by configuring the switched capacitor banks. In this way, the proposed DAL is compatible with the implementation of a digitally-controlled XO (DCXO), which is desired for many WSN [33]. In those applications, cheap quartz crystals are preferred, however, they usually have larger frequency variations and require frequency trimming.

\section{A. Oscillator Core}

The Pierce oscillator core uses an NMOS transistor to implement the negative $\mathrm{g}_{\mathrm{m}}$ for negative resistance. The bias current circuit provides a reconfigurable current for the oscillator from a $20 \mu \mathrm{A}$ bias current input to compensate the variations due to process spread, environmental fluctuation, or different quartz crystals. Since the noise of the crystal oscillator will be up-converted when it is used as the reference clock for a PLL, the noise of the crystal oscillator should be optimized. The ratio of the current mirror is minimized to reduce the noise contribution from the current mirror devices. The resistor $\mathbf{R}_{b}$ is set to $40 \mathrm{kohm}$ to bias the NMOS while avoiding loading the crystal quartz. The trip-point of the inverter-based buffer is optimized to equal the DC level of the crystal core, so that the gain of the inverter is maximized. As a result, it can amplify the signal of the oscillator core to rail-to-rail so that the inputreferred noise of the inverter is minimized.

The load capacitors $\mathrm{C}_{1(2)}$, equal to $2 \mathrm{C}_{\mathrm{L}}$, consist of two parts: on-chip switched capacitor banks $\mathrm{C}_{1 \mathrm{a}(2 \mathrm{a})}$ and the parasitics $\mathrm{C}_{1 \mathrm{~b}(2 \mathrm{~b})}$ due to on-chip routing, bonding and packaging, and $\mathrm{PCB}$ routing. $\mathrm{C}_{1 \mathrm{a}(2 \mathrm{a})}$ is programmable up to $16 \mathrm{pF}$, and is implemented with a $6 \mathrm{~b}$ switched capacitor bank (Fig. 10). $\mathrm{C}_{1 \mathrm{~b}(2 \mathrm{~b})}$ is about $4 \mathrm{pF}$, resulting in a maximum $(16 \mathrm{pF}+4 \mathrm{pF}) / 2=$ $10 \mathrm{pF}$ load capacitance. At start-up, the capacitor bank is switched dynamically, which disturbs the oscillation amplitude of the crystal oscillator. Assuming the charge on the capacitor stays the same when switching a capacitor, the voltage variation $\Delta V$ at nodes $\mathrm{XOP}$ and $\mathrm{XON}$ due to switching of the capacitor can be estimated as:

$$
\Delta V=\frac{V_{0}}{1+C_{0} / C_{u}},
$$




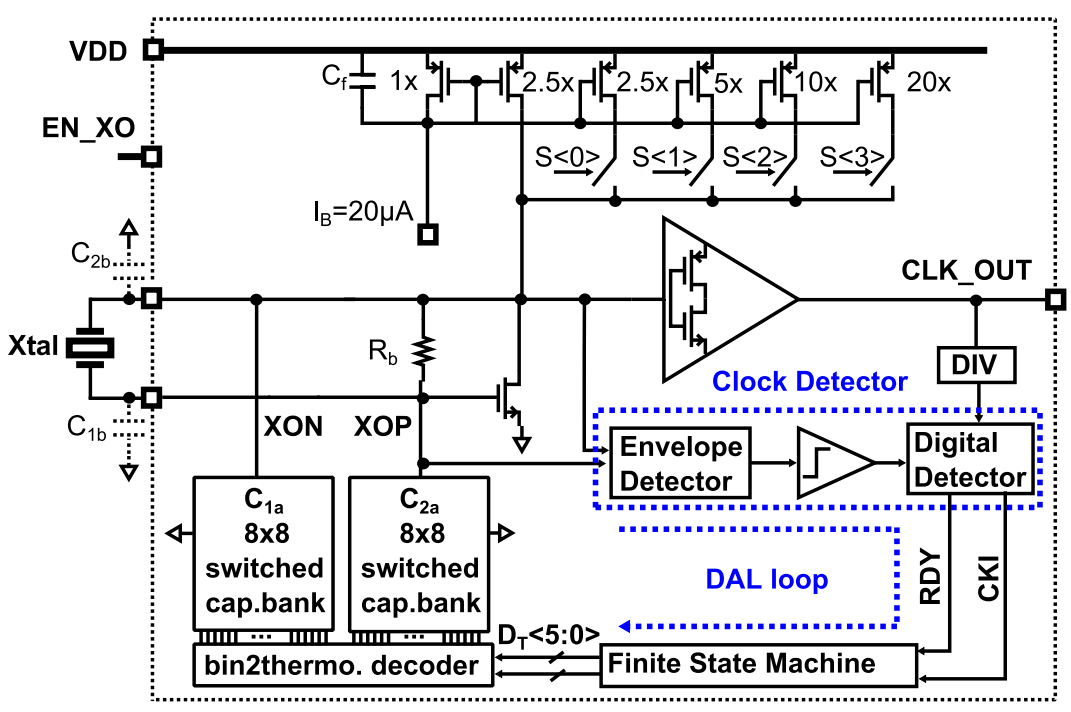

(a)

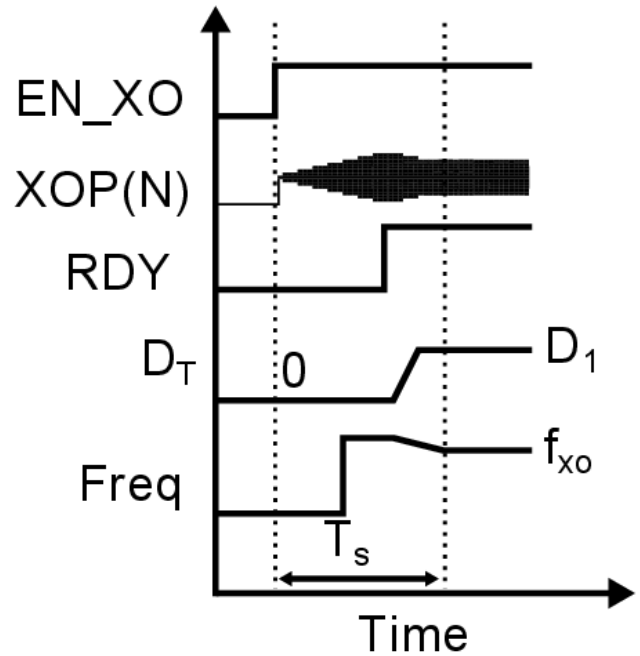

(b)

Fig. 9. Block diagram of the crystal oscillator with autonomous dynamically-adjusted load (DAL) (a) and a waveform illustration (b).

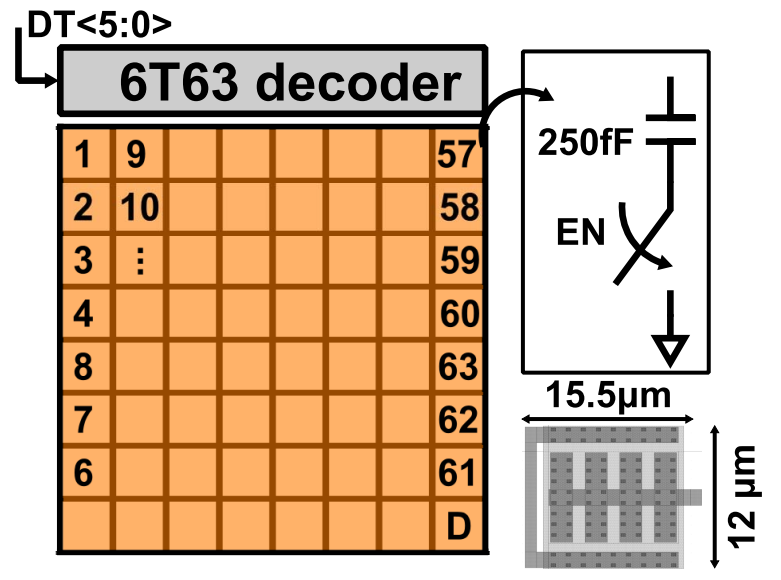

Fig. 10. The $6 \mathrm{~b}$ thermometer-encoded capacitor bank.

where $V_{0}$ and $C_{0}$ are the voltage and capacitance of the capacitor before switching the capacitor, and $C_{u}$ is the added capacitance. Depending on the switching moment, $C_{0}$ can be any value between $4 \mathrm{pF}$ and $20 \mathrm{pF}$, while $V_{0}$ should be around $0.5 V_{D D}$ because the capacitor is switched at the edge of the clock. The switching induced voltage variation $\Delta V$ starts with a relatively larger value $\left(\frac{V_{0}}{1+\left(C_{1 b}+C_{2 b}\right) / C_{u}}\right)$ at the beginning and then gradually reduces to a smaller value $\left(\frac{V_{0}}{1+\left(C_{1 a}+C_{2 a}+C_{1 b}+C_{2 b}\right) / C_{u}}\right)$ at the later stage of the start-up. Theoretically the unit capacitor should be as small as possible to minimize the voltage variation. However, this increases the complexity of the capacitor bank and therefore the parasitics. Therefore, in this work, a $6 \mathrm{~b}$ capacitor bank is chosen and this results in a 250fF LSB size. In addition, the capacitors are switched at the zero crossing point of XOP and XON when the differential charge in the load capacitors is minimum, so that the differential switching induced voltage variation is also reduced. The unit capacitor cell is implemented using a MIM (Metal-Insulator-Metal) capacitor in series with a complementary switch (Fig. 10).
The switches of the capacitor bank are carefully sized to trade-off between the quality factor of the capacitor bank and the induced parasitics. In this work, the switches are sized relatively large $(15 \mu \mathrm{m} / 0.1 \mu \mathrm{m})$ to assure sufficient quality factor (700). This is at the cost of an increase of the off-state parasitic capacitance $(1.26 \mathrm{pF}$ in total). Each time at start-up, by configuring the final settled value of $\mathrm{C}_{1(2)}$, the frequency of the oscillator in the stable phase is trimmed automatically. The tuning accuracy in this work is $<7 \mathrm{ppm}$ with a tuning range larger than $\pm 50 \mathrm{ppm}$, which is sufficient for many IoT applications, for example, BLE or IEEE802.15.4.

\section{B. Dynamically-Adjusted Load Circuits}

A feedback loop, which implements the dynamicallyadjusted load method, performs the detection function to monitor the oscillator amplitude and determines the moment to increase the load capacitance. It consists of a clock detector circuit and an FSM (Fig. 9(a)). The clock detection circuit includes two parts (Fig. 11): an amplitude detector which is composed of an envelope detector (ED) in series with a comparator, and a digital clock detector. The envelope detector and the comparator are continuously monitoring the amplitude of the crystal oscillator, by comparing with a reference voltage. Once the oscillator amplitude exceeds this threshold, the comparator output will trigger the FSM to generate a $6 \mathrm{~b}$ tuning code that gradually ramps up the switched capacitor bank to the final value.

The envelope detector extracts the amplitude information of the sinewave of the crystal oscillator. It uses a pseudodifferential architecture as shown in Fig. 11(a) to suppress the common-mode variations. The resistor $\mathrm{R}_{\mathrm{e}}$ and the capacitor $\mathrm{C}_{\mathrm{e}}$ are set to $55 \mathrm{kohm}$ and $2 \mathrm{pF}$ respectively, resulting in a $700 \mathrm{kHz}$ bandwidth, which effectively attenuates the high frequency components. This generates a relatively smooth output of the envelope detector, with an acceptable delay in the DAL loop (a few $\mu$ s). 


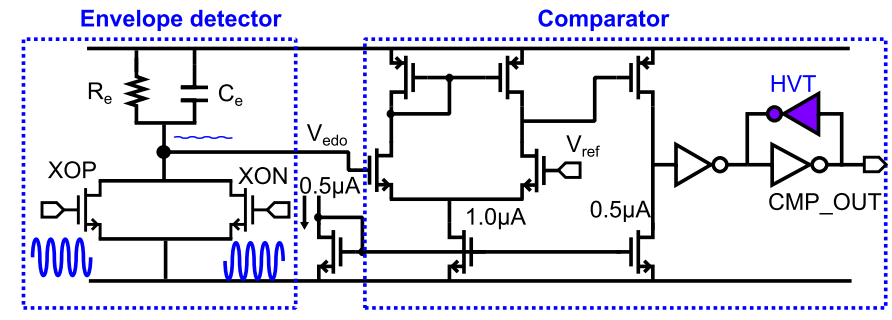

(a)

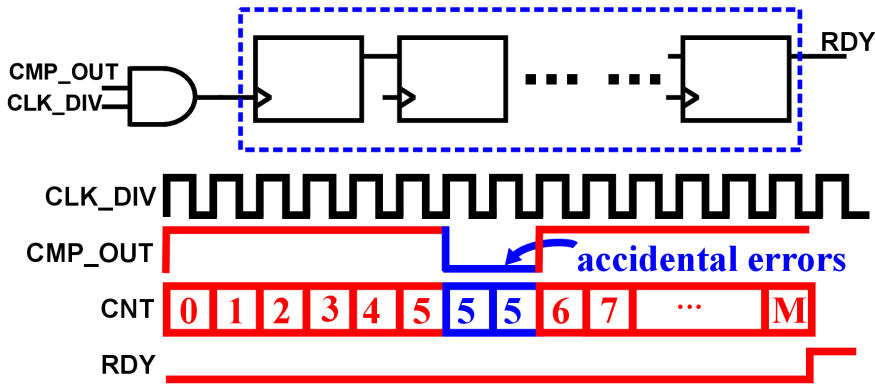

(b)

Fig. 11. The amplitude detection circuitry (a) and the digital detection circuitry (b).

The comparator is continuously comparing the ED output with a reference voltage. It consists of a three-stage opamp and a latch. The input stage consumes only $1 \mu \mathrm{A}$, and the second stage $0.5 \mu \mathrm{A}$. The bandwidth is set as $4 \mathrm{MHz}$, resulting in a negligible delay compared to that of the envelope detector. The third stage is an inverter, providing a rail-to-rail output. The voltage $\mathrm{V}_{\text {edo }}$ at the comparator input has ripples due to the limited high frequency attenuation of the envelope detector, resulting in glitches at the comparator output, which is not desired. In order to overcome this issue, a digital Schmidtt trigger is implemented using a cross-coupled latch (Fig. 11(a)) [34]. The hysteresis of the latch is designed to be higher than the ripple at the ED output to avoid oscillation at the comparator output. The reference voltage of the comparator uses a resistor-ladder based voltage divider from the bias circuits.

After the comparator indicates sufficient oscillation amplitude, a digital clock detection circuit is further used to ensure that the clock quality is sufficient before the load adaptation is initiated (Fig. 11(b)). The logic filters out accidental errors of the comparator, and will only proceed if $\mathrm{M}$ correct cycles are counted. The counter operates at a lower frequency (divided by 4$)$, resulting in an acceptable delay $(\sim 1 \mu \mathrm{s})$. Once the RDY becomes active, the FSM starts to function. It generates a 6-bit tuning code $\mathrm{D}_{\mathrm{T}}$ which increments from 0 to the desired value, to control the capacitor banks. The operation frequency of the FSM is kept relatively low (divided by 4), slowing down the switching transient meanwhile with an acceptable delay (maximum $10 \mu \mathrm{s}$ ). Moreover, the capacitor bank is thermometer-encoded instead of binary-encoded. In this way, the voltage fluctuations of the crystal oscillator during this transient are minimized, avoiding as much as possible clock glitches. In a dual-mode crystal oscillator [9], a long transition time $(130 \mu \mathrm{s})$ is used during switching between two modes. This is to assure that no glitches will happen because the clock

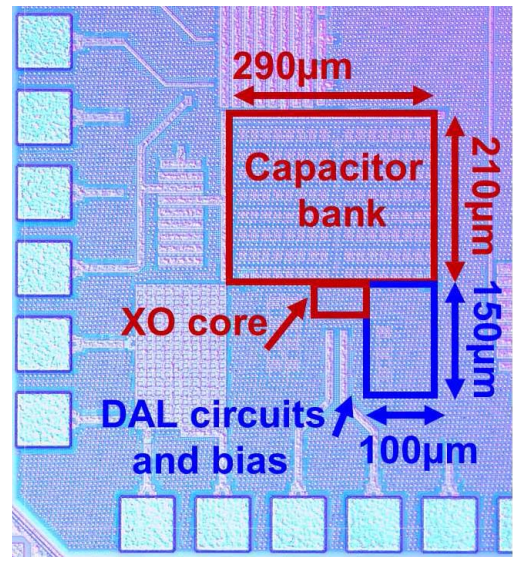

Fig. 12. Chip photo.

Amplitude Without DAL Frequency
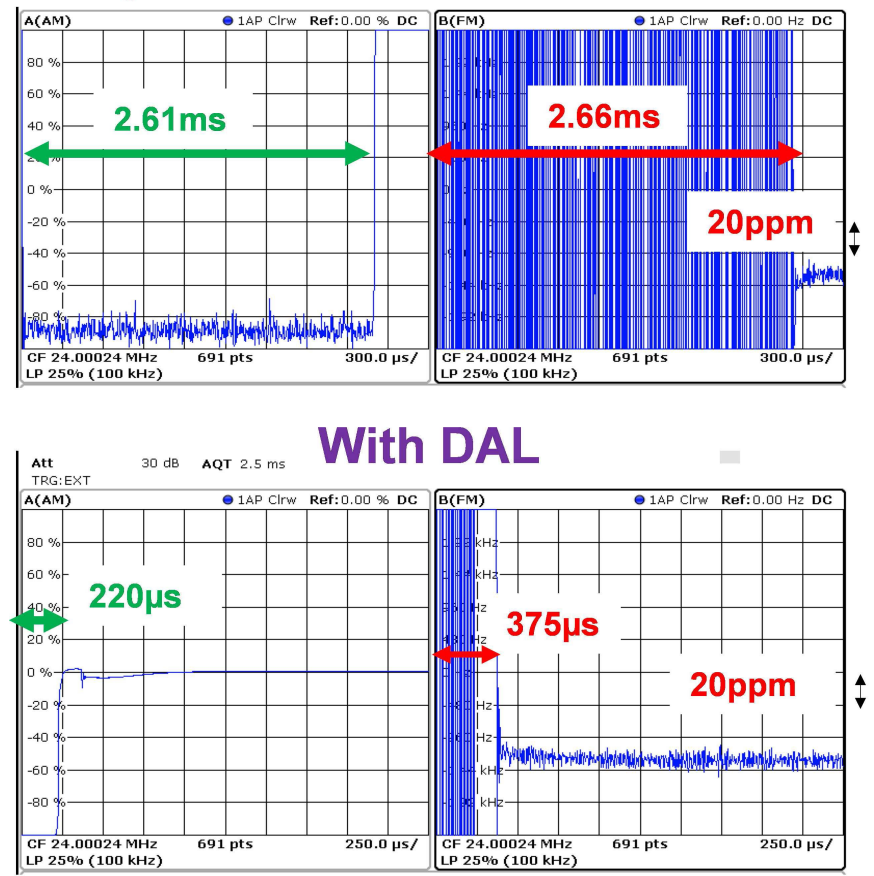

Fig. 13. Measured start-up behavior in two scenarios: without, with DAL.

has to be proper in both modes. In this work, at the start-up of the oscillator, a relative short transient time $(\sim 10 \mu \mathrm{s})$ is used to compromise between delay and possibility of glitches. After the start-up of the oscillator, the crystal oscillator clock will be used for the other circuits of the chip.

In practice, the circuits that are used for fast start-up (including the ED, the comparator, and the reference voltage) can be disabled once the output of the FSM increments to the expected value. This is not implemented in this chip.

\section{Measurements}

To verify the functionality of the proposed DAL method, a prototype of the test chip is implemented in 90nm LP CMOS as shown in Fig. 12. The core area is $0.072 \mathrm{~mm}^{2}$, including the load capacitor (84\%) and the feedback loop to implement the DAL method (10\%). A $24 \mathrm{MHz}$ quartz crystal, of which 

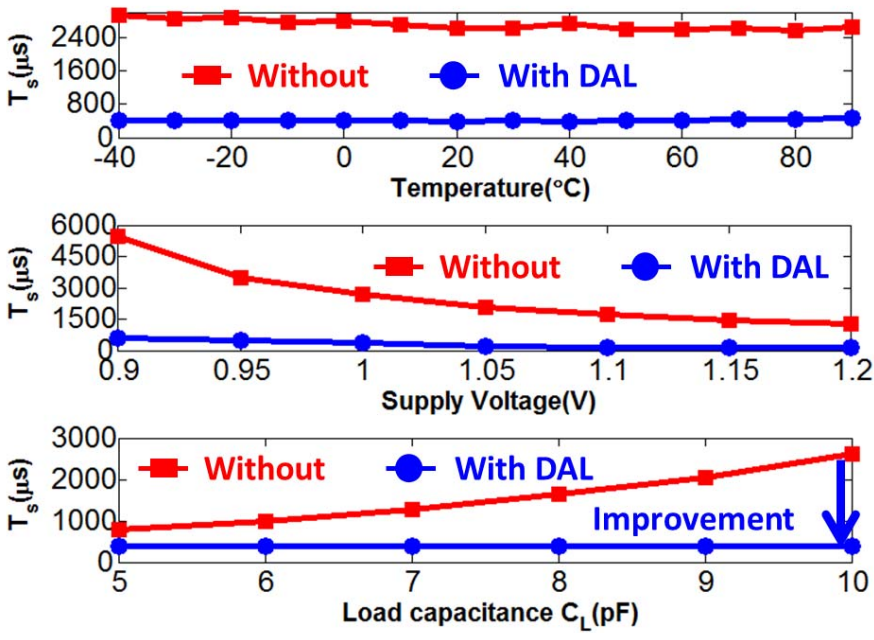

Fig. 14. Measured start-up time with respect to temperature, supply voltage and load capacitance variations.

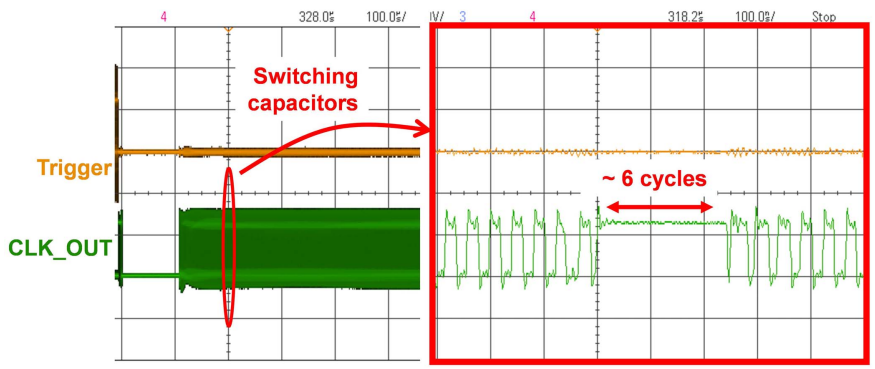

Fig. 15. Measured hang-up of the output clock during startup.

the estimated quality factor is 54800 , is used to verify the functionality of the chip. At $1 \mathrm{~V}$, the chip consumes $95 \mu \mathrm{W}$ in the steady state and the circuits to implement the DAL method consume $9 \mu \mathrm{W}$ extra at the start-up.

The start-up time is measured as follows: the CLK_OUT is measured utilizing the amplitude/frequency demodulation feature of the FSV Rohde\&Schwarz signal analyzer, because it is not desired to measure the amplitude of the oscillator directly by probing due to the large capacitive load (namely tens of $\mathrm{pF}$ ). In this way, the amplitude and frequency of the output clock can be measured without disturbing the load capacitance of the crystal oscillator. Fig. 13 shows the measured amplitude (left part) and frequency (right part) of the XO output CLK_OUT during the start-up, which comprises three phases. Before the oscillator starts up, the amplitude of CLK_OUT is low and the demodulated frequency is very noisy. Once the XO starts up, CLK_OUT will be detected but its frequency is not yet accurate and stable. After the load capacitor $\mathrm{C}_{1(2)}$ is correctly settled, the frequency will be stable. The start-up time is defined as the duration for the frequency to settle within $\pm 20 \mathrm{ppm}$ from the target frequency, which is well within the requirement of many IoT standards, e.g. BLE $( \pm 41 \mathrm{ppm})$ and IEEE802.15.4 ( $\pm 40 \mathrm{ppm})$ [1]. Without any start-up technique, the oscillator takes $2.66 \mathrm{~ms}$ to start up. With the DAL technique only, the frequency can settle within $375 \mu \mathrm{s}$, resulting in a $7 \times \mathrm{T}_{\mathrm{s}}$ reduction. By slightly increasing the power to $146 \mu \mathrm{W}$ for a higher $\mathrm{g}_{\mathrm{m}}$ of $1 \mathrm{mS}$,
$1 \mathrm{~V} \times 95.9 \mu \mathrm{A} \times 2.66 \mathrm{~ms}=255 \mathrm{~nJ}$

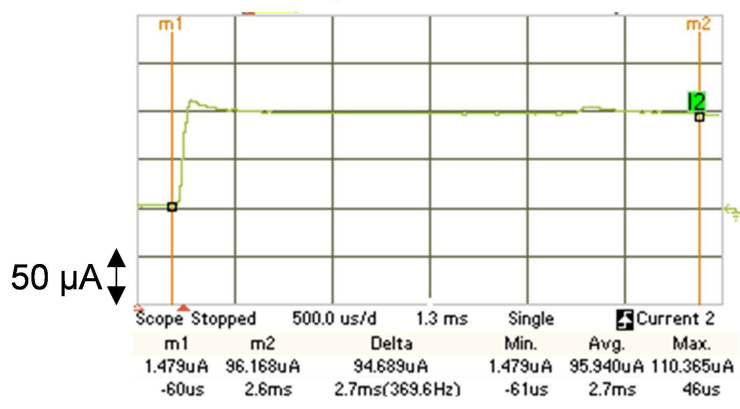

(a)

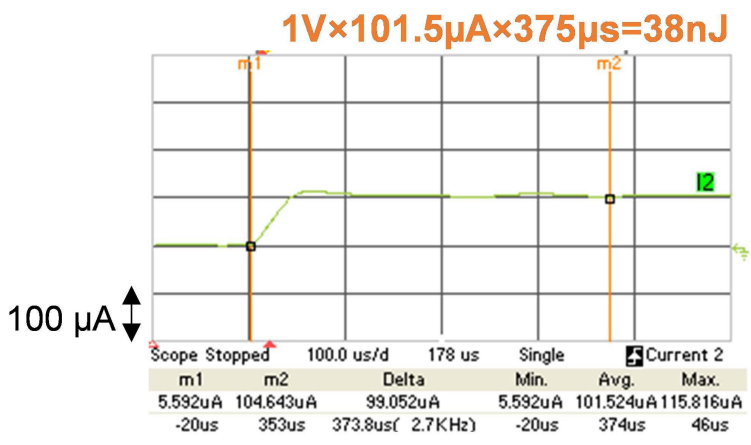

(b)

Fig. 16. Measured current profile without boosting technique (a), and with DAL (b).

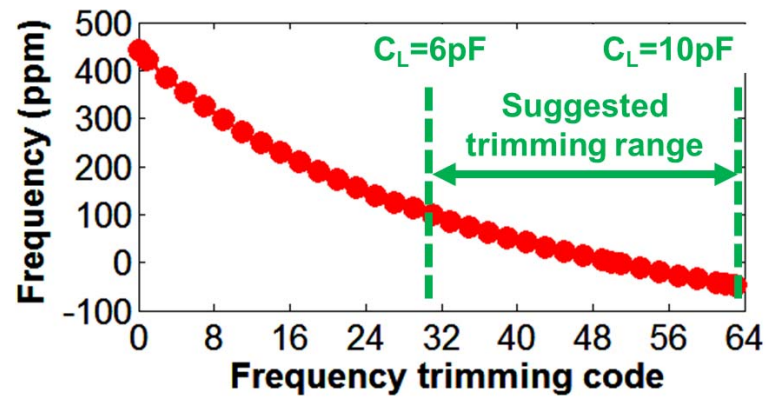

Fig. 17. Measured frequency trimming performance.

TABLE I

START-UP MEASUREMENTS USING THREE DifFERENT QUARTZ CRYSTALS

\begin{tabular}{|c|c|c|c|c|c|}
\hline & \multirow{2}{*}{$\begin{array}{c}\text { Crystal size } \\
\left(\mathrm{mm}^{3}\right)\end{array}$} & \multirow{2}{*}{$\begin{array}{c}\text { Frequency } \\
(\mathrm{MHz})\end{array}$} & \multicolumn{3}{|c|}{ Start-up time $(\mathrm{ms})$} \\
\cline { 4 - 6 } & & & Without & DAL & DAL $+\mathrm{g}_{\mathrm{m}}$ \\
\hline Crystal No. 1 & $5.0 \times 3.2 \times 1.0$ & 24 & 2.6 & 0.37 & 0.2 \\
\hline Crystal No. 2 & $5.0 \times 3.2 \times 1.0$ & 32 & 4.1 & 0.63 & 0.38 \\
\hline Crystal No. 3 & $4.0 \times 2.5 \times 0.8$ & 24 & 4 & 0.67 & 0.37 \\
\hline
\end{tabular}

the frequency can settle in $200 \mu \mathrm{s}$, resulting in $13.3 \times \mathrm{T}_{\mathrm{s}}$ reduction. If only the $g_{m}$ method is applied, it gives roughly $2 \times$ start-up time reduction. The $\mathrm{g}_{\mathrm{m}}$ can be further increased by increasing the power consumption, but that is not desired. As shown in Fig. 15, a temporary hang-up of the output clock CLK_OUT occurs during the startup of the oscillator. This is caused by the switching of the capacitor bank, which produces a temporary internal common mode voltage drop on nodes XOP and XON. The oscillator core is still running 
TABLE II

Performance Summary ANd Comparison With State-of-THE-ART

\begin{tabular}{|c|c|c|c|c|c|c|c|c|}
\hline & $\begin{array}{c}{[21]} \\
\text { JSSC'12 }\end{array}$ & $\begin{array}{c}{[29]} \\
\text { JSSC'16 }\end{array}$ & \multicolumn{2}{|c|}{$\begin{array}{c}{[24]} \\
\text { ISSCC'16 }\end{array}$} & $\begin{array}{c}30] \\
\text { JSSC'18 }\end{array}$ & $\begin{array}{c}{[23]} \\
\text { JSSC'18 }\end{array}$ & \multicolumn{2}{|c|}{ This work } \\
\hline Technology (nm) & 65 & 180 & \multicolumn{2}{|c|}{65} & 65 & 65 & \multicolumn{2}{|c|}{90} \\
\hline Core area $\left(\mathrm{mm}^{2}\right)$ & 0.15 & 0.12 & \multicolumn{2}{|c|}{0.08} & 0.09 & 0.023 & \multicolumn{2}{|c|}{0.072} \\
\hline Supply (V) & 1 & 1.5 & \multicolumn{2}{|c|}{1.68} & 1.0 & $0.35 / 0.7$ & \multicolumn{2}{|c|}{1.0} \\
\hline Frequency $(\mathrm{MHz})$ & 26 & 39 & \multicolumn{2}{|c|}{24} & 10 & 24 & \multicolumn{2}{|c|}{24} \\
\hline Load capacitance, $C_{\llcorner}(p F)$ & 8 & 8 & 6 & 9 & 9 & 6 & \multicolumn{2}{|c|}{10} \\
\hline Steady-state power $(\mu \mathrm{W})$ & 2180 & 181 & 393 & 693 & 23.6 & 31.8 & \multicolumn{2}{|c|}{95} \\
\hline Start-up time $(\mu \mathrm{s})$ & $3200^{*}$ & $158^{*}$ & $64^{*}$ & $435^{\star}$ & $11.3^{*}$ & $400^{*}$ & $375^{\text {t* }}$ & $200^{\text {t* }}$ \\
\hline Start-up time (cycles) & 83200 & 6162 & 1536 & 10440 & 113 & 9600 & 9000 & 4800 \\
\hline Total start-up energy (nJ) & 6976 & 349 & & 13.5 & 14.2 & 38 & 36.7 \\
\hline $\mathrm{T}_{\mathrm{s}}$ variation with Temp. & - & $<7 \%$ & $\pm 35 \%$ & $\pm 20 \%$ & $3 \%$ & $7.5 \%$ & $26.6 \%$ & $27.5 \%$ \\
\hline Temperature range $\left({ }^{\circ} \mathrm{C}\right)$ & - & -30 to 125 & \multicolumn{2}{|c|}{-40 to 90} & -40 to 85 & -40 to 90 & \multicolumn{2}{|c|}{-40 to 90} \\
\hline Crystal size $(\mathrm{mm} \times \mathrm{mm})$ & - & - & $3.2 \times 2.5$ & $2.0 \times 1.6$ & $\begin{array}{c}11.4 \times 4.7 \\
3.2 \times 2.5 \\
\end{array}$ & $3.2 \times 2.5$ & \multicolumn{2}{|c|}{$5.0 \times 3.2$} \\
\hline Fast start-up Technique & None & $\mathrm{Cl}+\mathrm{g}_{\mathrm{m}}$ & \multicolumn{2}{|c|}{ Dithered injection } & $\begin{array}{c}\text { Precisely- } \\
\text { Timed injection }\end{array}$ & $\begin{array}{c}\text { 3-stage } g_{m}+ \\
\text { SSCl }\end{array}$ & DAL & $\begin{array}{c}\text { \#DAL + } \\
g_{m}\end{array}$ \\
\hline Extra oscillator required & - & Yes & \multicolumn{2}{|c|}{ Yes } & Yes & Yes & \multicolumn{2}{|c|}{ No } \\
\hline
\end{tabular}

* start-up timer defined as the time it takes for the oscillation amplitude to reach $90 \%$ of its steady-state value

**start-up time defined as the time it takes for the oscillation frequency to settle within $\pm 20 \mathrm{ppm}$

\# In DAL $+g_{m}$ method, the power consumption for start-up up is increased, with respect to DAL only, to $146 \mu \mathrm{W}$

correctly, but the common-mode shift moves the oscillator signal temporarily out of the trip-point of the inverter buffer, thus resulting in a hang-up of the output clock CLK_OUT for approximately 6 cycles. This is not a problem because this only happens at the start-up when switching capacitors. After that, the capacitor digital control bits are static and no hangup will occur. In addition, the start-up time measurements are repeated with temperature variations, supply voltage variations and load variations (Fig. 14). With the temperature swept from $-40^{\circ} \mathrm{C}$ to $90^{\circ} \mathrm{C}$, the measured start-up time variation is $13 \%$ and $26.6 \%$ without/with DAL. No frequency trimming is performed and the frequency drifting is less than $20 \mathrm{ppm}$. With a swept supply voltage from $0.9 \mathrm{~V}$ to $1.2 \mathrm{~V}$, the measured start-up time variation is $66 \%$. The performance fluctuation is mainly due to the $\mathrm{g}_{\mathrm{m}}$ variation. Moreover, with the large load capacitance varying from $5 \mathrm{pF}$ to $10 \mathrm{pF}$, a very stable start-up performance (3\%) is achieved. This matches with the expected behavior as shown in Fig. 8(a).

To measure the energy during the start-up process, the realtime current profile of the supply voltage is captured using Keysight current analyzer N6705B LXI, as shown Fig. 16. The measured total energy is calculated based on the measured real-time current. With DAL enabled, the measured total startup energy is reduced from $255 \mathrm{~nJ}$ to $38 \mathrm{~nJ}$. Thanks to the lowpower circuit for start-up, the energy overhead is minimized, leading to an approximately $6.7 \times$ start-up energy reduction with a $7 \times$ start-up time reduction. When increasing $\mathrm{g}_{\mathrm{m}}$ and DAL are both applied at start-up, the start-up time reduction is further reduced to $13 \times$. But as mentioned before, increasing only the $\mathrm{g}_{\mathrm{m}}$ reduces the start-up time at a higher power consumption. Thus, the start-up energy reduction is similar as that with DAL applied only $(6.9 \times)$. The energy of the voltage reference generation is not included because it is located in a separate power domain with a separate supply voltage. With it included, the total start-up energy increases by only $1.5 \mathrm{~nJ}$ and $0.8 \mathrm{~nJ}$ in the scenario with DAL only and with both DAL and $\mathrm{g}_{\mathrm{m}}$.

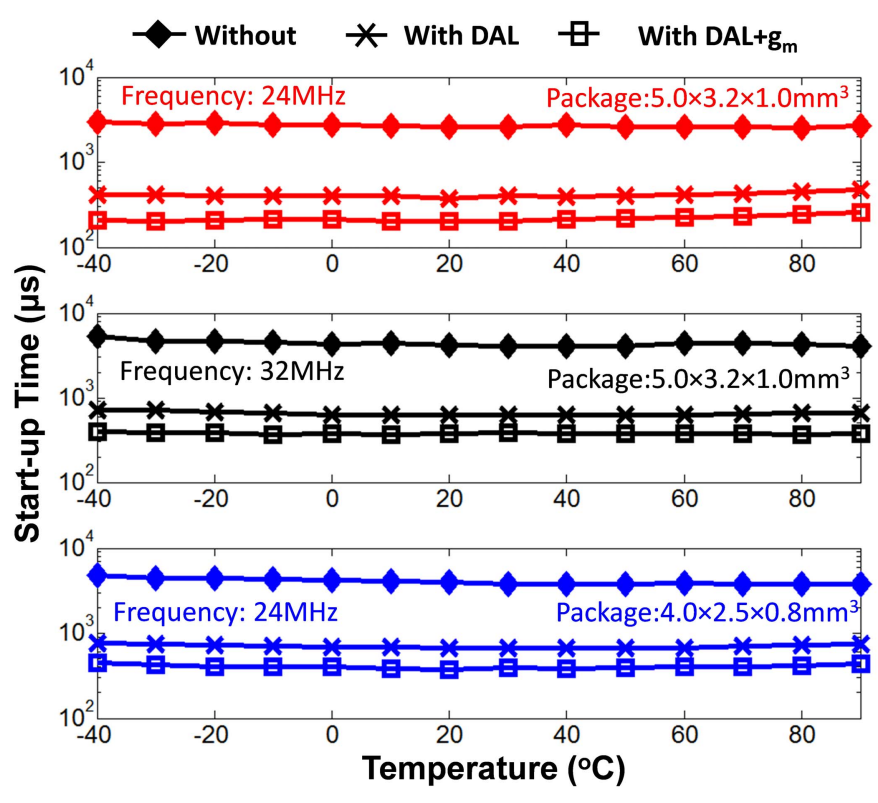

Fig. 18. Measured crystal oscillator start-up variations over temperature for three different crystal devices.

The frequency tuning range is measured using the Agilent $53230 \mathrm{~A}$ frequency counter. Each frequency is averaged over 1000 measurements. The measured frequency tuning range is roughly [-48ppm, $+440 \mathrm{ppm}$ (Fig. 17), among which [-48ppm, +102ppm] is suggested to be used for frequency trimming, because further reducing the load capacitance will degrade the performance of the XO. The averaged frequency trimming accuracy is $5 \mathrm{ppm}$, which is sufficient for many IoT applications, such as BLE or IEEE802.15.4. It achieves $-141 \mathrm{dBc} / \mathrm{Hz}$ measured phase noise at $100 \mathrm{kHz}$ frequency offset, which is good enough for most IoT applications, such as BLE or IEEE802.15.4.

To verify the validity of the proposed method, the measurement is repeated using three different quartz crystals with 
different package size, frequency or quality factor as shown in Table I. Crystal oscillators with higher quality factor quartz have longer start-up time. But the proposed DAL method can effectively reduce the start-up time for all the three crystal oscillators, and with both DAL and $\mathrm{g}_{\mathrm{m}}$ applied, the start-up time can be further reduced. In addition, the start-up time measurements against temperature variations are also repeated for all three crystal oscillator as shown in Fig. 18. It can be seen that the measured start-up time is also stable over temperature variations.

The performance of this work is summarized in Table II. Note that the absolute start-up time/energy can be influenced by many factors such as the crystal quality factor and package size. Nonetheless, the proposed method can improve both the start-up time and start-up energy thanks to its low-power start-up circuit. In addition, the start-up circuits are fully autonomously operated and insensitive to crystal oscillator frequency, making them suitable for future IoT applications.

\section{CONCLUSION}

A fast start-up crystal oscillator with a dynamically-adjusted load in 90nm CMOS is demonstrated. The proposed method features a fully autonomous operation, and has negligible overhead in power. Thanks to the DAL method, this work improves both the start-up time and the start-up energy, which is very attractive for future IoT applications.

\section{REFERENCES}

[1] Bluetooth Special Interest Group. (Dec. 2016) Specification of the Bluetooth System, Core Package Version 5.0, Bluetooth Specifications, Bluetooth Special Interest Group (SIG). [Online]. Available: https://www. bluetooth.org/en-us/specification

[2] Y. Cao, P. Leroux, W. De Cock, and M. Steyaert, "A 63,000 Q-factor relaxation oscillator with switched-capacitor integrated error feedback," in IEEE ISSCC Dig. Tech. Papers, Feb. 2013, pp. 186-187.

[3] Y. Satoh, H. Kobayashi, T. Miyaba, and S. Kousai, "A $2.9 \mathrm{~mW}$, +/- 85 ppm accuracy reference clock generator based on RC oscillator with on-chip temperature calibration," in Symp. VLSI Circuits Dig. Tech. Papers, Jun. 2014, pp. 1-2.

[4] M. Ding et al., "A $0.8 \mathrm{~V} 0.8 \mathrm{~mm}^{2}$ bluetooth 5/BLE digital-intensive transceiver with a $2.3 \mathrm{~mW}$ phase-tracking RX utilizing a hybrid loop filter for interference resilience in $40 \mathrm{~nm}$ CMOS," in IEEE ISSCC Dig. Tech. Papers, Feb. 2018, pp. 446-447.

[5] W. Sansen, Analog Design Essentials. New York, NY, USA: Springer, 2006.

[6] S. Farahvash, C. Quek, and M. Mak, "A temperature-compensated digitally-controlled crystal pierce oscillator for wireless applications," in IEEE ISSCC Dig. Tech. Papers, Feb. 2008, pp. 352-353.

[7] M.-D. Tsai, C.-W. Yeh, Y.-H. Cho, L.-W. Ke, P.-W. Chen, and G.-K. Dehng, "A temperature-compensated low-noise digitallycontrolled crystal oscillator for multi-standard applications," in IEEE Radio Freq. Integr. Circuits Conf. Dig. Tech. Papers, Jun. 2008, pp. 533-536.

[8] R. van Langevelde, M. van Elzakker, D. van Goor, H. Termeer, J. Moss, and A. J. Davie, "An ultra-low-power 868/915 MHz RF transceiver for wireless sensor network applications," in IEEE Radio Freq. Integr. Circuits Conf. Dig. Tech. Papers, Jun. 2009, pp. 113-116.

[9] D. Griffith, J. Murdock, P. T. Røine, and T. Murphy, "A $37 \mu \mathrm{W}$ dualmode crystal oscillator for single-crystal radios," in IEEE ISSCC Dig. Tech. Papers, Feb. 2015, pp. 104-105.

[10] S. Iguchi, T. Sakurai, and M. Takamiya, "A low-power CMOS crystal oscillator using a stacked-amplifier architecture," IEEE J. Solid-State Circuits, vol. 52, no. 11, pp. 3006-3017, Nov. 2017.

[11] A. Shrivastava, D. A. Kamakshi, and B. H. Calhoun, "A $1.5 \mathrm{nW}$, $32.768 \mathrm{kHz}$ XTAL oscillator operational from a $0.3 \mathrm{~V}$ supply," IEEE J. Solid-State Circuits, vol. 51, no. 3, pp. 689-696, Mar. 2016.
[12] K.-J. Hsiao, "A $1.89 \mathrm{nW} / 0.15 \mathrm{~V}$ self-charged $\mathrm{XO}$ for real-time clock generation," in IEEE ISSCC Dig. Tech. Papers, Feb. 2014, pp. 298-299.

[13] D. Yoon, T. Jang, D. Sylvester, and D. Blaauw, "A $5.58 \mathrm{nW}$ crystal oscillator using pulsed driver for real-time clocks," IEEE J. Solid-State Circuits, vol. 51, no. 2, pp. 509-522, Feb. 2016.

[14] S. Iguchi, A. Saito, Y. Zheng, K. Watanabe, T. Sakurai, and M. Takamiya, "93\% power reduction by automatic self power gating (ASPG) and multistage inverter for negative resistance (MINR) in $0.7 \mathrm{~V}$, $9.2 \mu \mathrm{W}, 39 \mathrm{MHz}$ crystal oscillator," in Proc. Symp. VLSI Circuits, Jun. 2013, pp. C142-C143.

[15] Y. Rajavi, M. M. Ghahramani, A. Khalili, A. Kavousian, B. Kim, and M. Flynn, "A 48-MHz differential crystal oscillator with $168-\mathrm{fs}$ jitter in 28-nm CMOS," IEEE J. Solid-State Circuits, vol. 52, no. 10, pp. 2735-2745, Oct. 2017.

[16] C. Elgaard and L. Sundström, "A $91.52 \mathrm{MHz} 840 \mu \mathrm{W}$ crystal oscillator in $28 \mathrm{~nm}$ FD-SOI CMOS for 5G applications," in Proc. ESSCIRC, Sep. 2017, pp. 247-250.

[17] A. Shrivastava, R. Yadav, and P. K. Rana, "Fast start-up crystal oscillator," U.S. Patent 8120439 , Feb. 21, 2012.

[18] D. N. Tran, "Crystal oscillator circuit having fast start-up and method therefor," U.S. Patent 7639097, Dec. 12, 2009.

[19] J. Lin, "A low-phase-noise 0.004-ppm/step DCXO with guaranteed monotonicity in the 90-nm CMOS process," IEEE J. Solid-State Circuits, vol. 40, no. 12, pp. 2726-2734, Dec. 2005.

[20] D. Griffith, F. Dülger, G. Feygin, A. N. Mohieldin, and P. Vallur, "A $65 \mathrm{~nm}$ CMOS DCXO system for generating $38.4 \mathrm{MHz}$ and a real time clock from a single crystal in $0.09 \mathrm{~mm}^{2}$," in IEEE Radio Freq. Integr. Circuits Conf. Dig. Tech. Papers, May 2010, pp. 321-324.

[21] Y. Chang, J. Leete, Z. Zhou, M. Vadipour, Y.-T. Chang, and H. Darabi, "A differential digitally controlled crystal oscillator with a 14-bit tuning resolution and sine wave outputs for cellular applications," IEEE J. Solid-State Circuits, vol. 47, no. 2, pp. 421-434, Feb. 2012.

[22] S. Zaliasl et al., "A $3 \mathrm{ppm} 1.5 \times 0.8 \mathrm{~mm} 21.0 \mu \mathrm{A} 32.768 \mathrm{kHz}$ MEMS-based oscillator," IEEE J. Solid-State Circuits, vol. 50, no. 1, pp. 291-302, Jan. 2015.

[23] K.-M. Lei, P.-I. Mak, M.-K. Law, and R. P. Martins, "A regulationfree sub-0.5-V 16-/24-MHz crystal oscillator with 14.2-nJ startup energy and 31.8- $\mu \mathrm{W}$ steady-state power," IEEE J. Solid-State Circuits, vol. 53, no. 9, pp. 2624-2635, Sep. 2018.

[24] D. Griffith, J. Murdock, and P. T. Røine, "A 24 MHz crystal oscillator with robust fast start-up using dithered injection," in IEEE ISSCC Dig. Tech. Papers, Jan./Feb. 2016, pp. 104-105.

[25] E. A. Vittoz, M. G. R. Degrauwe, and S. Bitz, "High-performance crystal oscillator circuits: Theory and application," IEEE J. Solid-State Circuits, vol. SSC-23, no. 3, pp. 774-783, Jun. 1988.

[26] A. Rusznyak, "Start-up time of CMOS oscillators," IEEE Trans. Circuits Syst., vol. CAS-34, no. 3, pp. 259-268, Mar. 1987.

[27] U. Karthaus, "A differential two-pin crystal oscillator-Concept, analysis, and implementation," IEEE Trans. Circuits Syst. II, Exp. Briefs, vol. 53, no. 10, pp. 1073-1077, Oct. 2006.

[28] Y. I. Kwon, S.-G. Park, T.-J. Park, K.-S. Cho, and H.-Y. Lee, "An ultra low-power CMOS transceiver using various low-power techniques for LR-WPAN applications," IEEE Trans. Circuits Syst. I, Reg. Papers, vol. 59, no. 2, pp. 324-336, Feb. 2012.

[29] S. Iguchi, H. Fuketa, T. Sakurai, and M. Takamiya, "Variation-tolerant quick-start-up CMOS crystal oscillator with chirp injection and negative resistance booster," IEEE J. Solid-State Circuits, vol. 51, no. 2, pp. 496-508, Feb. 2016.

[30] H. Esmaeelzadeh and S. Pamarti, "A quick startup technique for high- $Q$ oscillators using precisely timed energy injection," IEEE J. Solid-State Circuits, vol. 53, no. 3, pp. 692-702, Mar. 2018.

[31] M. Ding et al., "A $95 \mu \mathrm{W} 24 \mathrm{MHz}$ digitally controlled crystal oscillator for IoT applications with $36 \mathrm{~nJ}$ start-up energy and $>13 \tilde{\mathrm{A}}-$ start-up time reduction using a fully-autonomous dynamically-adjusted load," in IEEE ISSCC Dig. Tech. Papers, Feb. 2017, pp. 90-91.

[32] M. Ding et al., "Ultra-low-power clock generation for IoT radios," in Proc. Adv. Analog Circuit Design Workshop, 2018.

[33] D. Ruffieux et al., "A $3.2 \times 1.5 \times 0.8 \mathrm{~mm}^{3} 240 \mathrm{nA} 1.25$-to-5.5 V $32 \mathrm{kHz}-\mathrm{DTCXO}$ RTC module with an overall accuracy of $\mu 1 \mathrm{ppm}$ and an all-digital $0.1 \mathrm{ppm}$ compensation-resolution scheme at $1 \mathrm{~Hz}$," in IEEE ISSCC Dig. Tech. Papers, Jan./Feb. 2016, pp. 208-209.

[34] A. Paidimarri, D. Griffith, A. Wang, G. Burra, and A. P. Chandrakasan, "An RC oscillator with comparator offset cancellation," IEEE J. Solid-State Circuits, vol. 51, no. 8, pp. 1866-1877, Aug. 2016. 


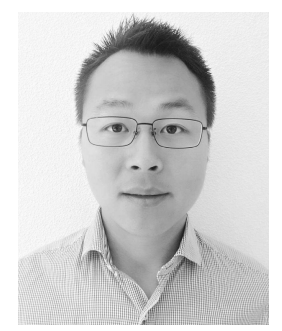

Ming Ding received the B.E. degree from the Huazhong University of Science and Technology, China, in 2009, and the M.Sc. degree from the Eindhoven University of Technology, The Netherlands, in 2011. In 2011, he started as a Researcher at the imec/Holst Centre, The Netherlands. Since then, he has been working on data converter and ultra-lowpower wireless research and design.

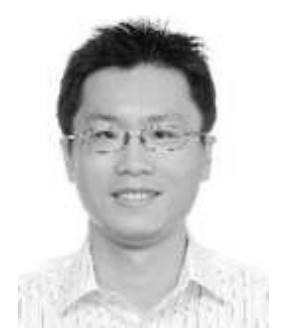

Yao-Hong Liu received the Ph.D. degree from National Taiwan University, Taiwan, in 2009. Since 2010, he joined imec, The Netherlands. His current position is the Principal Membership of Technical Staff, and he is leading the development of the ultra-low power RFIC design. His research focuses are energy-efficient wireless transceivers and RF sensing for IoT. He currently serves as a Technical Program Committee of the IEEE ISSCC and RFIC Symposium.

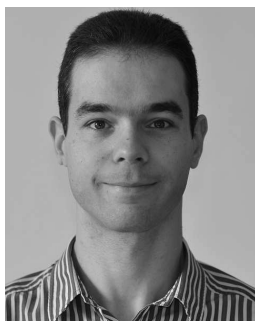

Pieter Harpe (SM'15) received the M.Sc. and $\mathrm{Ph} . \mathrm{D}$. degrees from the Eindhoven University of Technology, The Netherlands, in 2004 and 2010, respectively. In 2008, he started as a Researcher at the imec/Holst Centre, The Netherlands. Since then, he has been working on ultralow-power wireless transceivers, with a main focus on ADC research and design. In 2011, he joined the Eindhoven University of Technology, where he is currently an Associate Professor on low-power mixed-signal circuits. $\mathrm{He}$ is a co-organizer of the yearly workshop on advances in analog circuit design and the Analog Subcommittee Chair for the ESSCIRC Conference. He also served as an ISSCC ITPC Member and the IEEE SSCS Distinguished Lecturer and is a recipient of the ISSCC 2015 Distinguished Technical Paper Award.

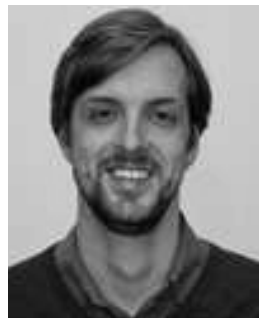

Christian Bachmann received the Ph.D. degree in electrical engineering in 2011. He is the Program Manager of imec's ULP Wireless Systems Program. He joined imec in 2011, working on ultralow-power wireless communication systems, digital baseband processing, and hardware/software codesign. In his previous work, he has covered various wireless communication solutions for $802.11 \mathrm{ah} \mathrm{Wi-}$ Fi, Bluetooth LE, 802.15.4 (Zigbee), ultra-wideband impulse radio, and others. Prior to joining imec, he has been researching hardware-accelerated power estimation for VLSI systems both with Infineon Technologies and Graz University of Technology, Graz, Austria.

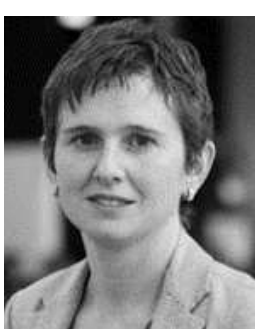

Kathleen Philips received the Ph.D. degree in electrical engineering. He is the Program Director of imec for the IoT. He has 20 years of experience in the domain of low power mixed-signal, $\mathrm{RF}$, and integrated system design. She started her career at Philips Research, The Netherlands, working on analog and mixed-signal circuits. She joined the imec/Holst Centre in 2007, where she is currently leading a program on ultra-low power wireless, processing and sensing systems. This is a part of open innovation collaboration, together with local and international industry. The research targets applications in the area of infrastructure and person-centric IoT systems, with a focus on ultra-low power communication and sensing.

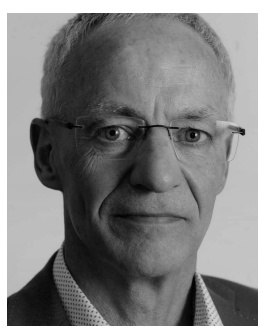

Arthur Van Roermund was born in Delft, The Netherlands, in 1951. He received the M.Sc. degree in EE from the Delft University of Technology in 1975 and the Ph.D. degree in applied sciences from K U Leuven, Belgium, in 1987. From 1975 to 1992, he was with Philips Research Laboratories, Eindhoven. From 1992 to 1999, he was a Full Professor at the EE Department, Delft University of Technology. In 1999, he joined the Eindhoven University of Technology, where he was the Chairman of the Mixed-Signal Microelectronics Group until 2017, and the Director of the Research of the TU/e-EE Department from 2002 to 2012. He co-organized the yearly workshop on Advanced Analog Circuit Design from 2001 to 2012. Since 2017, he has been an Emeritus Professor. He was a member of three international assessment panels: Politecnico di Milano, Italy, in 2007; Aalto University, Finland, in 2009; KTH, Stockholm, Sweden, in 2012. He has published over 700 articles and 30 books. $\mathrm{He}$ is a co-editor of another 12 books. In 2004, he achieved the Simon Stevin Meester Award for his scientific and technological achievements. 